\title{
Review of conceptual and systematic progress of precision irrigation
}

\author{
Zhongwei Liang ${ }^{1,2,3^{*}}$, Xiaochu Liu ${ }^{1,2,3}$, Jinrui Xiao ${ }^{1,2}$, Changhong Liu ${ }^{2}$ \\ (1. Guangdong Engineering Research Centre for High Efficient Utility of Water/Fertilizers and Solar Intelligent Irrigation, \\ Guangzhou University, Guangzhou 510006, China; \\ 2. School of Mechanical and Electrical Engineering, Guangzhou University, Guangzhou 510006, China; \\ 3. Advanced Institute of Engineering Science for Intelligent Manufacturing, Guangzhou University, Guangzhou 510006, China)
}

\begin{abstract}
Precision irrigation, defined as accurate and appropriate agricultural techniques characterized by optimal management and best collaboration of various irrigation factors, attracts great attention and obtains wide employments in different irrigation conditions or cultivation processes. Moreover, it becomes well-established in major areas of agricultural researches and across the broad spectrum of agricultural techniques especially in specific sectors of scientific frontiers, including soil quality, irrigation scheduling, water resource distribution, crop productivity, tillage management, climate adaptation, and environment monitoring, etc. This paper reviews the research developments and integrated applications of precision irrigation in typical domains of mechanism and performance, covering key aspects such as process optimization, schedule modelling, and effectiveness evaluation, indicating that advanced irrigation optimization methods support higher productivity of crop field and better environmental conditions of soil; Current schedule modelling techniques provide a set of instructive demonstrations and heuristic descriptions for the working principles of precision irrigation and the quantitative assessments of irrigation productivity; The novel investigation on effectiveness evaluation is extremely significant to obtain higher infiltration efficiency, simultaneously to achieve the optimized irrigation qualities for water balance condition, soil water redistribution, and soil moisture uniformity so that the effectiveness quality of irrigation infiltration could be improved remarkably. It is concluded that precision irrigation owns an outstanding collaborating capability and possesses much better working advancement in typical calibration indexes of cultivation accuracy and infiltration efficiency, meanwhile, a high agreement between the predicted and actual irrigation effectiveness could be expected. This novel irrigation review concentrating on the conceptual and systematic progress should be promoted constructively to improve the quality uniformity for precision irrigation and its constructive influences in different applications, and to facilitate the integrated management of agricultural production by higher irrigation efficiency consequently.
\end{abstract}

Keywords: precision irrigation, process optimization, schedule modelling, effectiveness evaluation, conceptual and systematic progress

DOI: $10.25165 /$ j.ijabe.20211404.5463

Citation: Liang Z W, Liu X C, Xiao J R, Liu C H. Review of conceptual and systematic progress of precision irrigation. Int J Agric \& Biol Eng, 2021; 14(4): 20-31.

\section{Introduction}

As agriculture spends most of the water resources in the world, water scarcity and soil quality have become major constraints to human development and water balance condition in the past 20 years, precision irrigation has been investigated and emphasized due to the remarkable population increment, extreme environmental condition, and excessive water demands ${ }^{[1,2]}$. It is well known that water conservation through precision irrigation, alleviates a large portion of the burden of water demand ${ }^{[3]}$. As some adaptive measures in the irrigated agriculture nowadays include fallowing land, shifting cropping patterns, increased groundwater pumping, reservoir storage capacity expansion, and increased production of risk-averse crops $^{[1]}$, it is important to

\section{Received date: 2019-10-14 Accepted date: 2020-09-09}

Biographies: Xiaochu Liu, $\mathrm{PhD}$, Professor, research interest: intelligent agriculture equipment and high-performance irrigation engineering, Email: gdliuxiaochu@gzhu.edu.cn; Jinrui Xiao, Lecturer, research interest: agriculture engineering, Email: xjr@gzhu.edu.cn; Changhong Liu, Associate Professor, research interest: intelligent control of irrigation equipment, Email: changhongliu@gzhu.edu.cn.

*Corresponding author: Zhongwei Liang, PhD, Professor, research interest: agriculture engineering and intelligent precision irrigation. School of Mechanical and Electrical Engineering, Guangzhou University, Guangzhou 510006, China. Tel: +86-20-39366923, Email: liangzhongwei@gzhu.edu.cn. introduce precision irrigation techniques to ensure the sustainable usage of water/soil resource and feed the enormous population all around the world ${ }^{[4]}$. In this paper precision irrigation is defined as the high-efficient and appropriate employment of water and soil resources to acquire the optimum growth result of crop plants and reduce adverse environmental impacts, it is a collaborative mechanism that controls the land productivity, maximizes the revenue and minimizes the conditional impact on surroundings by automating the complete irrigation performances ${ }^{[5,6]}$. Simultaneously, as a unique irrigation operation, it also involves the optimal management and best coordination of all participant factors of the agricultural irrigation process. This technique could be applicable to all operational irrigation methods such as precise drip irrigation, subsurface deficit irrigation, and adaptively alternate irrigation, at appropriate spatial and temporal scales. Precision irrigation comprises a wide range of irrigation systems, both at on-farm plot, or scheme levels, corresponding to very different agricultural requirements and cultivation monitoring reality ${ }^{[7,8]}$. Recently, extensive efforts have been made to survey the amount and distribution of irrigation water withdrawals ${ }^{[9]}$, as the soil water storage, circulation efficiency of groundwater, moisture distribution efficiency, and moisture diffusivity, are all necessary to promote the working efficiency of precision irrigation remarkably. It is also imperative to determine the exact effect of soil water redistribution for irrigation management, as well as with 
irrigation productivity and transpiration consumption. Some advanced irrigation control models including soil water balance models, hydrologic models, Decision Support System for Agrotechnology Transfer (DSSAT) models, Geographic Information System (GIS)-based models, Information and Communications Technology (ICT) and Internet of Things (IoT) methods, have already been used widely in process optimization, schedule modelling and effectiveness evaluation ${ }^{[10,11]}$, which are discussed in this paper. Consequently, the functional classification of precision irrigation systems is a fundamental initial step to serve as a basis for its conceptual and systematic review, contributing to the sustainability and stability of irrigated agriculture demanding high-efficient management of environmental resources under existing environmental constraints ${ }^{[12]}$.

Based on the above-mentioned introduction, the rationale and significance of precision irrigation for agricultural production could be fully acknowledged. In order to demonstrate the conceptual and systematic progress of precision irrigation techniques, here this paper proposes a constructive overview concerning its process optimization in Section 2; then the representative schedule modelling practices of precision irrigation are enumerated by Section 3; Section 4 discusses the effectiveness evaluation of precision irrigation in details, thus its complex influence mechanism in actual performances could be highlighted; Based on these subsections, Section 5 presents the future research trends of precision irrigation; and Section 6 concludes this paper eventually.

\section{Process optimization of precision irrigation}

In the interest of implementing persistent aggrandizement of precision irrigation effectiveness, which needs high-efficient and supportive irrigation equipment that recognizes the conditional equilibrium in water-saving operation and crop productivity intensification ${ }^{[13]}$, the process optimization of precision irrigation should be emphasized and realized by balancing the requirements of condition and cost. Effective testing and tentative simulation are very important to facilitate water and energy application for system design and irrigation supervision so that the main objectives of irrigation process optimization are maximizing water application efficiency and distribution uniformity, minimizing water loss and soil erosion while keeping the agricultural irrigation costs at a minimized scale.

From the review of recently-published literature, it could be learned that irrigation optimization should be performed during the designing stage of the irrigation system, including irrigation setups, pumping systems, sprinkler nozzles, irrigation network, and intelligent control platform. Table 1 gives a progress demonstration of irrigation optimization. There are a set of investigations concerning the combination of Remote Sensing (RS) and GIS for precision irrigation. Various optimization methods used for actual irrigation, including linear programming (LP), non-linear programming (NLP), dynamic programming (DP), genetic algorithms (GA), and simulated annealing (SA), have all been employed frequently for better quality and higher productivity of crop cultivation. For example, an optimization method was presented to improve the water-usage efficiency in tea irrigation and analyze the complex correlation between irrigation efficiency and farming characteristics using the Tobit method ${ }^{[39]}$. Hintsa et al. ${ }^{[40]}$ focused on the coefficient coordination between crop irrigation requirement, vapor pressure deficit (VPD), water use efficiency (WUE), and field productivity, so that their study encourages the optimal implementation of precise deficit irrigation

and reduces a remarkable amount of irrigation water by keeping stable crop productivity. A mathematical model called Reservoirs Operation Optimization considering sediment evacuation (RESOOSE) was used to optimize irrigation deficit. Using RESOOSE model the irrigation deficit indexes in soil field could be reduced by $16 \%$ while maintaining existing benefits ${ }^{[41]}$.

\section{Table 1 Research progresses in the process optimization domain of precision irrigation}

Methods and algorithms

1 MOPECO

2 Taguchi orthogonal experiments

3 Fuzzy comprehensive evaluation

4 AquaCrop method Dynamic programming

5 with successive Approximations (DPSA)

6 Ant colony optimization (ACO) method

7 Genetic algorithms

Integrated multi-objective

8 stochastic fuzzy programming

Controlled showering

9 optimization (CSO) Transfer 10 Meta-heuristic algorithms equipment for monitoring moisture infiltration rate of soil ${ }^{[36-38]}$

Nowadays, accurate estimation of soil water balance is significant to support the availability of water resources and optimal irrigation management, which makes the process optimization of precision irrigation necessary. The determination of soil/water balance parameters such as precipitation rate, evapotranspiration ratio, soil moisture, and the leaching behavior of environmental nutrient phosphorus were explained and evaluated by the use of lysimeters ${ }^{[42]}$. Mao et al. ${ }^{[43]}$ and Zurweller et al. ${ }^{[3]}$ respectively derived water balance model to simulate both downward and upward soil water movement, and optimal Nitrogen and irrigation management in heterogeneous unsaturated zones. Since the accuracy of soil water content and evapotranspiration simulation affect crop yield simulations, DSSAT is a useful suite of field-scale, process-based crop models to simulate crop growth and process optimization ${ }^{[44,45]}$. By comparison, HYDRUS is an effective hydrological model to investigate the probable effects of subsurface drainage on soil water dynamics ${ }^{[46-48]}$. By using these two models the scheduling procedure of hydrologic needs can be simulated $^{[49,50]}$. When it comes to the utilization of DSSAT models in precise drip irrigation, DSSAT was used on the growth and yield occasions of the drip-irrigated crops ${ }^{[2,51]}$. Accordingly, Bhunia et al. ${ }^{[52]}$, Asfandyar et al. ${ }^{[53]}$, and Feng et al. ${ }^{[54]}$ mapped the spatial variation of water resources for irrigation purposes, and the impact quantification of center pivot irrigation system uniformity as well ${ }^{[4]}$, all these endeavors facilitate the process optimization of advanced irrigation techniques greatly.

On the topic of adaptive process optimization, the optimum abstraction of groundwater resources was estimated for sustainable management of precision irrigation ${ }^{[55]}$. Similarly, a novel 
adaptive process optimization for the real-time monitoring of pressurized water irrigation pipeline network has been proposed, by employing multi-objective genetic approaches ${ }^{[56]}$. This approach realizes the optimum operational sectoring to increase economic profit and decrease consumption cost, whilst satisfies the crop cultivation demand by considering the temporal balance between soil water content (SWC), soil evaporation, and infield spatial infiltration variability. A novel parameter optimization method using Adaptive Network-based Fuzzy Inference System (ANFIS) based upon orthogonal irrigation experiment, which could be suitable to the parametric optimization of precision irrigation process $^{[57]}$.

To summarize the process optimization of precision irrigation, it could be observed that based on these mentioned attempts and preparations, more advanced optimization techniques for precision irrigation were targeted and investigated to obtain higher agriculture yield and irrigation qualities with a minimum cost; especially, it could also be learned that the intelligent optimization approaches for precision irrigation control, the adaptive equilibrium in irrigation parameter selection, and the collaborative coordination of influential factors for soil moisture uniformity and agricultural crop productions, need to be explored further in future.

\section{Schedule modelling of precision irrigation}

Concerning appropriate schedule modelling of precision irrigation, there exist traditional researches paid their main attentions on scheduling the crop yield per unit area, by distributing applicable water resource to specific ranged fields according to their corresponding irrigation requirements in soil/water content, vapor pressure deficit, and groundwater quality for irrigation use. In the past several years, some scholars concluded that those effective scheduling models characterized by optimum agreement between their modeled results and actual observed outcomes, demonstrate certain inaccuracies and uncertainties regrettably ${ }^{[58]}$. In order to deal with this problem, some recent investigations acknowledged that a nonlinear system can be simulated by the integration of linear sub-systems, which has already been confirmed as a reliable schedule modelling technique for the authentication of non-linear optimization systems in precise drip and alternative irrigation. Furthermore, Liang et al. have paid their endeavor on the concentration estimation of effectiveness calibration for precision irrigation by using turbulent flow properties and neural network, thereafter a multi-dimensional fuzzy correlation computation approach applicable for flow energy distribution and clustering characteristics could be provided ${ }^{[59,60]}$, thus a versatile modelling algorithm for intelligent scheduling of precise drip irrigation, covering such indexes as water use efficiency, consumption of transpiration, saturated hydraulic conductivity, and water balance condition, could be expected.

On the other side, the new era of big data and ICT make it possible to have a larger amount of agricultural information available, leading to the development and promotion of new prediction tools for the schedule modelling of precision irrigation $^{[61,62]}$. Besides, some related research works on sensor cloud have primarily focused on the challenges of Wireless Sensor Network (WSN)-based applications. Smart irrigation enables the collection of agricultural data and employment of automated farming techniques so that IoT is introduced widely to give farmers quick access to develop schedule modelling and smart irrigation system $^{[63]}$. IoT has a unique capacity to remotely monitor essential irrigation variables such as soil moisture and water infiltration concentration, and remotely operate the accompanied irrigation equipment ${ }^{[64,65]}$, it is expected to reduce the number of human labour required and increase the accuracy of schedule modelling. Through improving soil moisture content and saturated hydraulic conductivity, IoT will considerably enhance the schedule modelling efficiency and agricultural productivity for practical irrigation performance ${ }^{[66,67]}$. In this manner, more research endeavors should be made for affecting horticulture to brilliant using IoT progresses in advanced irrigation systems ${ }^{[68,69]}$.

Table 2 Research progresses in the schedule modelling domain of precision irrigation

\begin{tabular}{|c|c|c|}
\hline \multicolumn{2}{|r|}{ Methods and algorithms } & Objectives and intentions \\
\hline 1 & $\begin{array}{l}\text { Mixed integer quadratic } \\
\text { programming (MIQP) }\end{array}$ & $\begin{array}{l}\text { Improve the efficiency of agricultural irrigation } \\
\text { in soil salinity concentration, water drop } \\
\text { penetration, and transpiration }{ }^{[70-73]}\end{array}$ \\
\hline 2 & $\begin{array}{l}\text { Simulated annealing } \\
\text { algorithm }\end{array}$ & $\begin{array}{l}\text { Making the objective function value obtained } \\
\text { from precision irrigation is close to the global } \\
\text { optimum }^{[74,75]}\end{array}$ \\
\hline 3 & $\begin{array}{l}\text { Particle swarm } \\
\text { optimization (PSO) }\end{array}$ & $\begin{array}{l}\text { Search the solution space intelligently and find } \\
\text { out the best solution in precision irrigation } \\
\text { schedule }^{[7,8]}\end{array}$ \\
\hline 4 & $\begin{array}{l}\text { Bee colony and invasive } \\
\text { weed optimization } \\
\text { (BCIWO) }\end{array}$ & $\begin{array}{l}\text { Highlight the irrigation characteristics with crop } \\
\text { cultivation process from chaotic data }{ }^{[76,77]}\end{array}$ \\
\hline 5 & $\begin{array}{l}\text { RZWQM (Root } \\
\text { water quality me }\end{array}$ & $\begin{array}{l}\text { Used for quantifying the effects of moisture } \\
\text { infiltration rates on soil-crop systems due to } \\
\text { accurate simulation of farmland water and } \\
\text { nutrient cycling }{ }^{[78]}\end{array}$ \\
\hline 6 & $\begin{array}{l}\text { Shuffled frog leaping } \\
\text { algorithm (SFLA) }\end{array}$ & $\begin{array}{l}\text { Ensuring a low-pressure irrigation flow for } \\
\text { high-efficient soillwater storage in crop } \\
\text { cultivation }^{[79-81]}\end{array}$ \\
\hline 7 & GIS-col & $\begin{array}{l}\text { The addition of high efficient irrigation } \\
\text { improves the cultivation properties of crops }{ }^{[58,82]}\end{array}$ \\
\hline 8 & $\begin{array}{l}\text { NSGA-II (Non- } \\
\text { dominated sorting } \\
\text { genetic algorithm) }\end{array}$ & $\begin{array}{l}\text { Developed a systematic model to predict the } \\
\text { moisture infiltration, soil salinity concentration, } \\
\text { and circulation efficiency of groundwater }{ }^{[83,84]}\end{array}$ \\
\hline 9 & $\begin{array}{l}\text { DSSAT (Decision } \\
\text { support system for } \\
\text { agrotechnology } \\
\text { Transfer) }\end{array}$ & $\begin{array}{l}\text { Applied the combined integrated irrigation with } \\
\text { decision-making process to irrigation support for } \\
\text { uplifting the circulation efficiency of } \\
\text { groundwater }{ }^{[85-89]}\end{array}$ \\
\hline 10 & ISAREG model & $\begin{array}{l}\text { Predicted the moisture infiltration rate of soil in } \\
\text { high accuracy }{ }^{[90-92]}\end{array}$ \\
\hline
\end{tabular}

For the purpose of maximizing per-unit crop productivity, a water requirement-based schedule system could be established and employed for the precise scheduling of water distribution efficiency (deficient irrigation). According to this novel conception Pawar et al. ${ }^{[93]}$ improved water productivity and cumulative infiltration ratio by using the calibrated AquaCrop model as well. Sepideh et al. ${ }^{[94]}$ also presented a systematic logical model for decision-making to evaluate technical reliability and schedule modelling of agricultural water utilization, which was merited by using layer-structured modular consisting of a set of applicable schedule modules to achieve an unstructured assessment for accurate irrigation schedule. By reference to these investigations, the complicated effectiveness of precise alternate irrigation were studied on the yield scheduling and irrigation efficiency of crop plant ${ }^{[95]}$, in more relevant studies Conesa et al. ${ }^{[96]}$ analyzed the constructive influences of precise deficit irrigation on scheduled productivity or infiltration uniformity; Evan et al. ${ }^{[61]}$ designed an effective and precise schedule simulation to optimally control the lawn irrigation demonstrated by Figure 1; Tsang et al. ${ }^{[97]}$ employed the artificial intelligence approach combining the neural network and logic calculation together to develop an optimal irrigation schedule strategy for water balance condition; Linker et al. ${ }^{[98]}$ described a 
high-efficient process modelling method to determine the optimized irrigation schedules for different crop-irrigation seasons. Recently research progresses concerning the schedule modeling based upon different influential factors such as soil salinity concentration, water balance condition, relative proportions of deep drainage and tail water, and water distribution efficiency, can be searched ${ }^{[99]}$

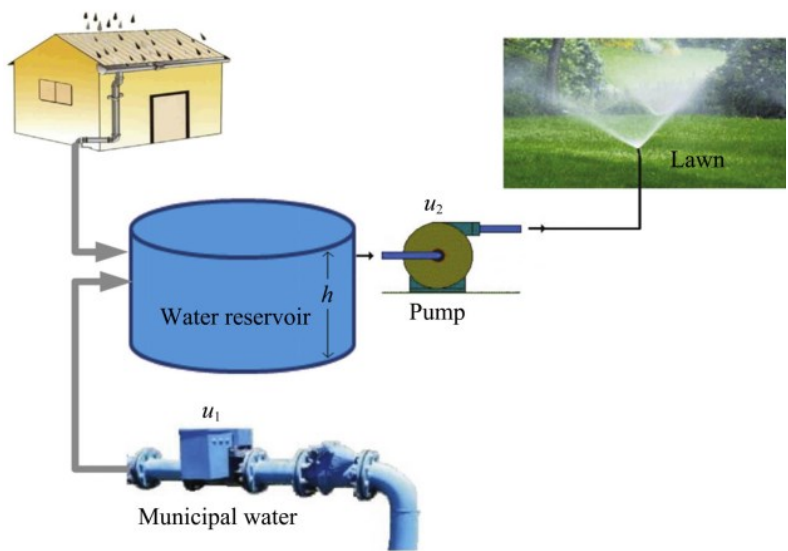

Figure 1 Schematic of rooftop water harvesting (RWH) for lawn irrigation $^{[61]}$

Based on a comprehensive survey, Table 2 also presents the latest research progresses in the schedule modelling domain of precision irrigation, all these mentioned studies contribute greatly to the most-developed progress that can be employed extensively in the schedule modelling conditions of precision irrigation. Although most of them only focused on the pure irrigation planning and infiltration modelling processes that describe the growth stage of irrigated crop and variation of soil characteristics, a more deliberate analysis dealing with inherent characteristics and correlative influence is absent in the current technical development of precision irrigation, therefore some difficult problems concerning accurate irrigation scheduling and their correspondingly influence mechanisms are still unstudied and unsettled, unfortunately. An efficient and accurate scheduling implementation of precision irrigation will facilitate the cultivation monitoring and effectiveness upgrading for crop growth or in-field productivity; thereafter, the instructive assessments of correlative impact caused from all participant factors of precision irrigation schedule modelling, for instance, soil water content, surface runoff and drainage, infield infiltration rate, and water drop penetration time, need to be developed and promoted further.

\section{Effectiveness evaluation of precision irrigation}

As it is well known that efficient utilization of water and soil resource is becoming increasingly essential for irrigation profitability improvement, so that the effectiveness evaluation of precision irrigation, especially on water use efficiency, infiltration rate, moisture diffusivity, cultivation water requirement, and crop productivity, is significant and necessary to meet the higher requirements of agriculture production nowadays. In order to make research preparation for the irrigation effectiveness evaluation, Henrique et al. ${ }^{[100]}$ dimensioned the potential effectiveness of drip irrigation using the calibrated Food and Agriculture Organization - Agroecological Zone Model (FAO-AZM), and paying their high attention to the calibrated levels of cultivation water supply simultaneously. Similarly, Luo et al. $^{[101]}$ investigated the quantitative impacts of water-saving sprinkling on weed growth and plant spread in rice fields, and found that the novel water-saving sprinkling method they proposed not only decreases irrigation water amount greatly but also promotes water productivity and irrigation effectiveness remarkably. According to this realistic demand, Christopher et al. ${ }^{[102]}$ introduced an innovative effectiveness evaluation method that aims to identify predominant geochemical changes in the groundwater system, providing a reliable and accurate tool to determine infiltration opportunity time and evaluate irrigation effectiveness in the subjects of moisture infiltration, water balance condition, and soil water storage. More relevant researches and on-the-spot investigations on the latest achievements concerning the effectiveness evaluation and performance assessment for precision irrigation can also be referenced ${ }^{[103]}$. Some existing difficult problems, such as the effectiveness comparisons and correlative analysis between irrigation schedules, the energy consumption of irrigation network, the optimal relative proportions of deep drainage and tail water, and multi-objective parametric optimization subject to uncertain agriculture conditions, could be solved in return ${ }^{[104]}$.

Table 3 Research progresses in the effectiveness evaluation domain of precision irrigation

\begin{tabular}{|c|c|c|}
\hline & Methods and algorithms & Objectives and intentions \\
\hline 1 & $\begin{array}{l}\text { Analytic hierarchy } \\
\text { evaluation }\end{array}$ & $\begin{array}{l}\text { Evaluate the project decision-making, the } \\
\text { organization planning, and the operation } \\
\text { management }{ }^{[105,106]} \text {. }\end{array}$ \\
\hline 2 & $\begin{array}{l}\text { Group dynamics } \\
\text { effectiveness index (GDEI) }\end{array}$ & $\begin{array}{l}\text { Measure the irrigation group effectiveness } \\
\text { by identifying different dimensions and } \\
\text { relative importance }{ }^{[104]} \text {. }\end{array}$ \\
\hline 3 & $\begin{array}{l}\text { Irrigation effectiveness } \\
\text { allocation coefficient }\end{array}$ & $\begin{array}{l}\text { Study the optimal water allocation } \\
\text { coefficient of irrigation effectiveness for } \\
\text { water balance conditions }{ }^{[96,107]} \text {. }\end{array}$ \\
\hline 4 & Hydrological drought index & $\begin{array}{l}\text { Helping farmers to manage the risk of } \\
\text { irrigation water scarcity in crop } \\
\text { cultivation }{ }^{[100]} \text {. }\end{array}$ \\
\hline 5 & $\begin{array}{l}\text { ANFIS (Adaptive network- } \\
\text { based fuzzy inference } \\
\text { system) }\end{array}$ & $\begin{array}{l}\text { Used for measuring irrigation water } \\
\text { effectiveness and its impact on productivity } \\
\text { growth rates } \\
{[41,108] \text {. }}\end{array}$ \\
\hline 6 & $\begin{array}{l}\text { CWSI (crop water stress } \\
\text { index) and time threshold } \\
\text { (CWSI-TT) }\end{array}$ & $\begin{array}{l}\text { Automatically monitoring the influence of } \\
\text { irrigation seasons on soil evaporation, and } \\
\text { moisture diffusivity }{ }^{[61,98]}\end{array}$ \\
\hline 7 & Water stress-coupled model & $\begin{array}{l}\text { Measuring the growth of plants for the } \\
\text { cultivation properties of crops }{ }^{[13,109]}\end{array}$ \\
\hline 8 & $\begin{array}{l}\text { Coefficient of long distance } \\
\text { sediment transportation and } \\
\text { distribution }\end{array}$ & $\begin{array}{l}\text { Based on the investigation on current } \\
\text { management technologies of typical } \\
\text { irrigation systems }{ }^{[110]} \text {. }\end{array}$ \\
\hline 9 & $\begin{array}{l}\text { DEA (data envelopment } \\
\text { analysis) and Malmquist } \\
\text { index }\end{array}$ & $\begin{array}{l}\text { Evaluates the effectiveness of agricultural } \\
\text { irrigation according to the circulation } \\
\text { efficiency of groundwater }{ }^{[55,111,112]} \text {. }\end{array}$ \\
\hline 10 & $\begin{array}{l}\text { Precipitation effectiveness } \\
\text { index }(\mathrm{PE})\end{array}$ & $\begin{array}{l}\text { Determining a suitable climate } \\
\text { classification system through comparison of } \\
\text { different aridity indices }{ }^{[101,113]} \text {. }\end{array}$ \\
\hline
\end{tabular}

It is also noteworthy to point out that the effectiveness impacts of irrigation intervals on crop productivity and quality coefficients have already been studied ${ }^{[110]}$. Since the remarkable impacts of specific irrigation approaches on plant growth are important in the statistic domain, the persistent influences of waste water irrigation on the electrical conductivity of field soil, moisture content, saturated hydraulic conductivity, and other soil quality indexes in practical field conditions, have been evaluated ${ }^{[114]}$. Their result comparison shows that its effectiveness influences on soil field should be determined according to actual site environment. Discrepancies between them are due to specific waste water and soil properties, climate conditions, and moisture evaporation. On the other side, CROPWAT was capable of quantifying the variation 
tendency of the actual irrigation schedule to improve the water balance of agro-ecosystems. Meanwhile Smith et al. ${ }^{[15]}$ demonstrated the application efficiency using a similar irrigation modelling technique for high-flow bay accordingly. Furthermore, in order to highlight the constructive impacts of crop cultivation approaches and precise deficit irrigation, Safi et al. ${ }^{[16]}$ implemented orthogonal irrigation experiments concentrating on the treatments and evaluations of direct seeding and precise deficit irrigation. According to the schematic diagram plotted by Figure 2, full irrigation is recommended first to achieve the highest crop yield with low transpiration rate and drainage consumption, then water deficit during the later stage is highly recommended for irrigation management if the economic benefits, water equilibrium condition, and irrigation efficiency be considered in the studied field region.

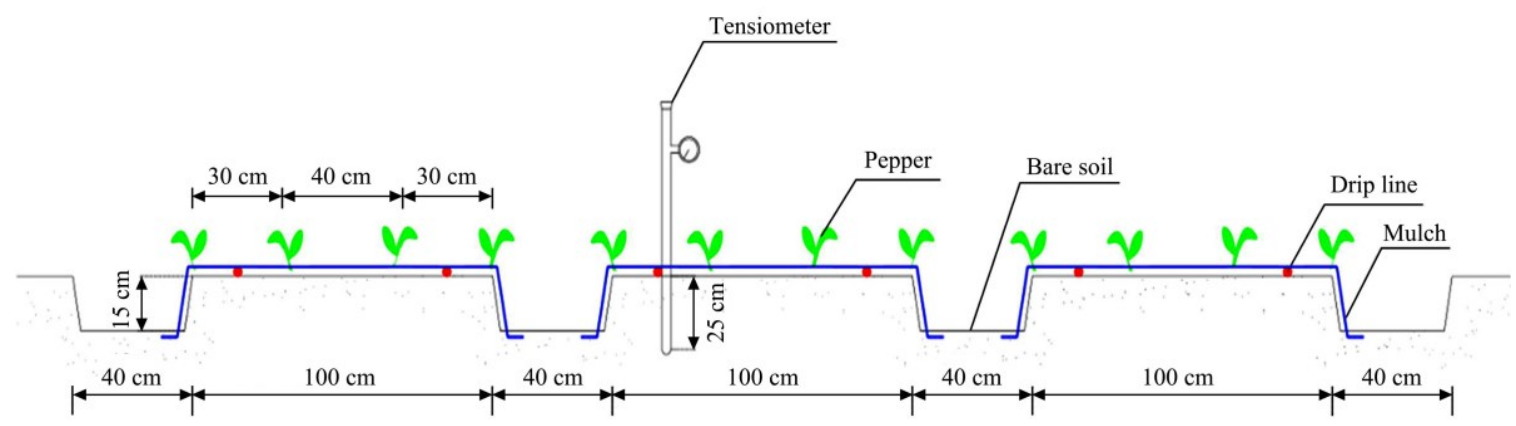

Figure 2 Schematic diagram describing the network layout of experimental irrigation plot ${ }^{[43]}$

As the complicated correlation between soil organic matter, effective cation exchange capacity (ECEC), exchangeable bases, and hydrogen ion concentration $(\mathrm{pH})$ was defined, Adejumobi et al. ${ }^{[17]}$ determined the effectiveness indexes of precision irrigation on soil quality status. Since waste water use in precision irrigation becomes a widely accepted operation to satisfy the rapid-increasing water demands in dry areas ${ }^{[18]}$, the crop yield could be promoted remarkably during the high-efficient irrigation operations in the beginning but reduced in the low-efficient irrigation operations, as Figure 3 presents their detailed evolution throughout irrigation operation processes. At the same time, Warwick et al. ${ }^{[119]}$ investigated the diurnal factors to quantify the performance effectiveness of irrigation efficiency. Simultaneously, they also applying three-dimensional mathematical simulations to approximate the day-time constructive influences with minimum measurement/ computation errors, thereafter they further investigated the emerging effectiveness of precision irrigation in certain conditions of shallow-rooted crop cultivation. Accordingly, Mojtaba et al. ${ }^{[120]}$ and Liang et al. ${ }^{[121]}$ also assessed the distribution uniformity of moisture variations in precision irrigation occasions when magnetic water was applied; David et al. ${ }^{[122]}$ investigated the complicated impacts of nutrient deficiencies
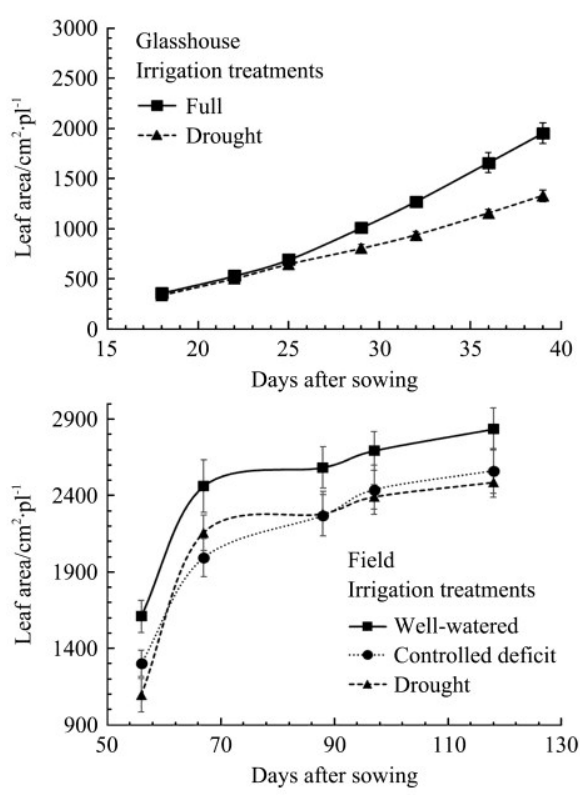

considering the interpretation of plant water status, herein Figure 4 shows the complicated effects of nitrogen and irrigation treatments on maize leaf area development in the glasshouse (upper figures) and field studies (lower figures) respectively, which further verifies the experimental principles they summarized.

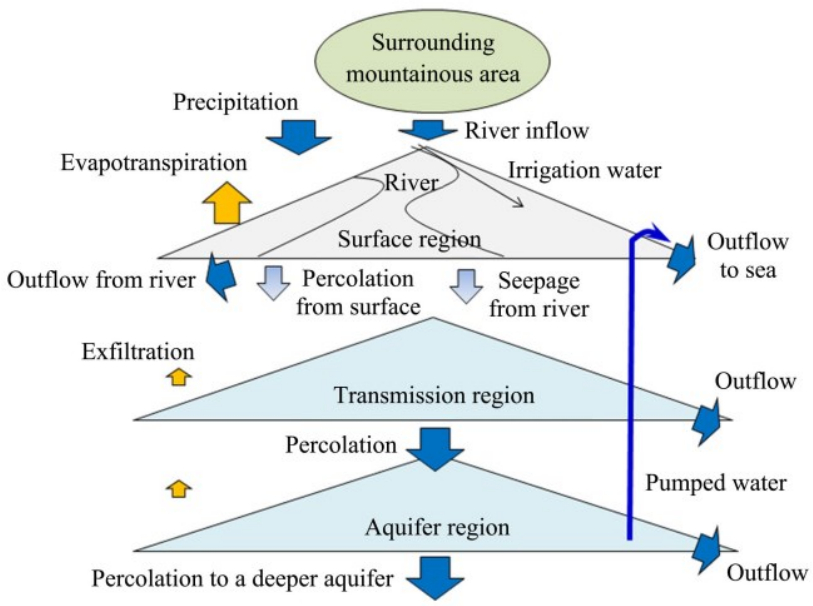

Figure 3 Concept of hydrologic cycle in precision irrigation research $^{[104]}$
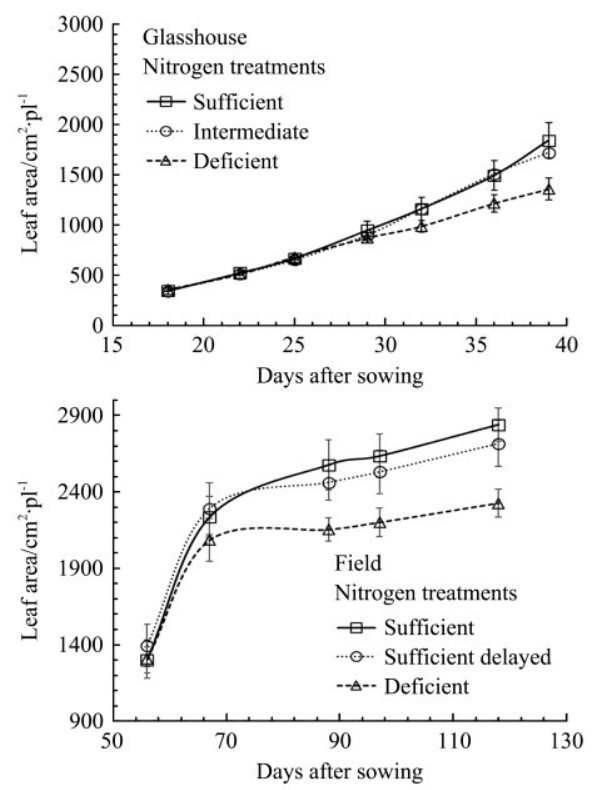

Figure 4 Influences of nitrogen and irrigation treatments on leaf area ${ }^{[122]}$ 
According to the development tendency of intelligent evaluation for precision irrigation effectiveness, Ramesh et al. and Vinoth et al. proposed IoT framework to improve agriculture yield by scheduling irrigation and fertilization effectively based on the crops' current requirements ${ }^{[123]}$, environmental conditions, and weather forecasts ${ }^{[124]}$. Keswani et al. ${ }^{[125]}$ relied on independent IoT enabled WSN framework consisting of soil moisture (MC) probe, soil temperature measuring device, environmental temperature sensor, humidity sensing device, moisture sensor, daylight intensity device (light dependent resistor), to acquire real-time farm information of irrigation effectiveness through multi-point measurement ${ }^{[9,126]}$. Moreover, IoT and sensors were employed to efficiently record plant data and watering needs ${ }^{[127]}$, thereafter the effectiveness evaluation approach was implemented with a mobile phone application interface that could be used to continuously monitor and control the efficient watering system. Since all these effectiveness evaluation technologies have been introduced to the implementation occasions of precision irrigation, their productive influences on the irrigation quality and relevant working properties should be discussed for the interests of effectiveness promotion.

Since the identification and assessment of optimal irrigation performance should be studied to determine the exact effectiveness level of precision irrigation, Önder et al. ${ }^{[12]}$ introduced a risk assessment procedure to quantify the mostappropriate effectiveness indexes in the actual irrigation process. Based on this assessment $\mathrm{Ge}$ et al. ${ }^{[128]}$ took representative irrigation treatments to learn the complicated effect of sprinkling time intervals on the crop growth situation. Furthermore, Table 3 demonstrates current research progresses in the effectiveness evaluation of precision irrigation. Using a new drought index ${ }^{[129]}$, a set of useful predicted soil moisture data could be obtained from a variable infiltration capacity (VIC) estimation over the irrigated area, they monitored the profound influence of dry climate on surface runoff and drainage, soil $\backslash$ water redistribution effect, and moisture diffusivity by using applicable effectiveness evaluation mode. Pawlowski et al. ${ }^{[130]}$ also presented the effectiveness study and practical evaluation for a greenhouse irrigation system. Figure 5 describes the comparison of water volume for precision irrigation management and water balance simulation model respectively, and Figure 6 gives the research progress and equipment development ${ }^{[57,103]}$, which provides effective and stable evaluation methods for precision irrigation effectiveness as required.
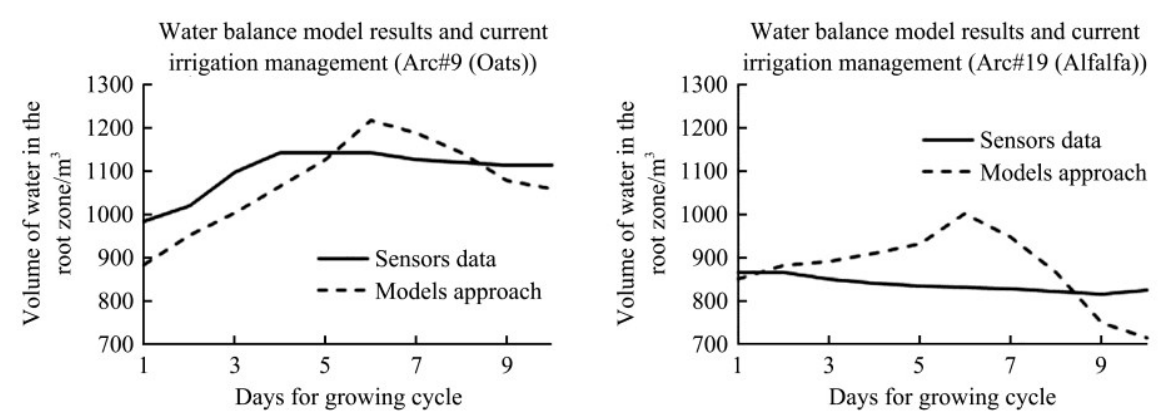

a.
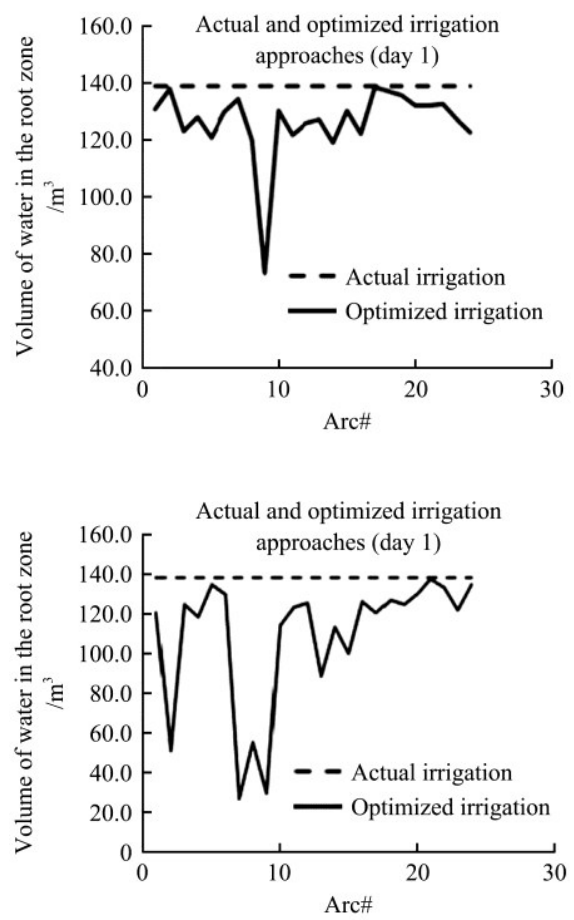

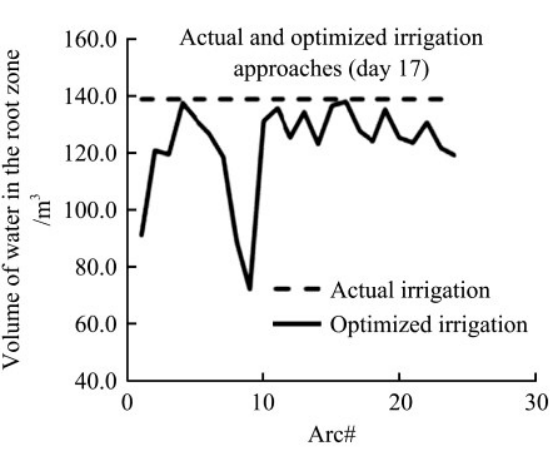

b.
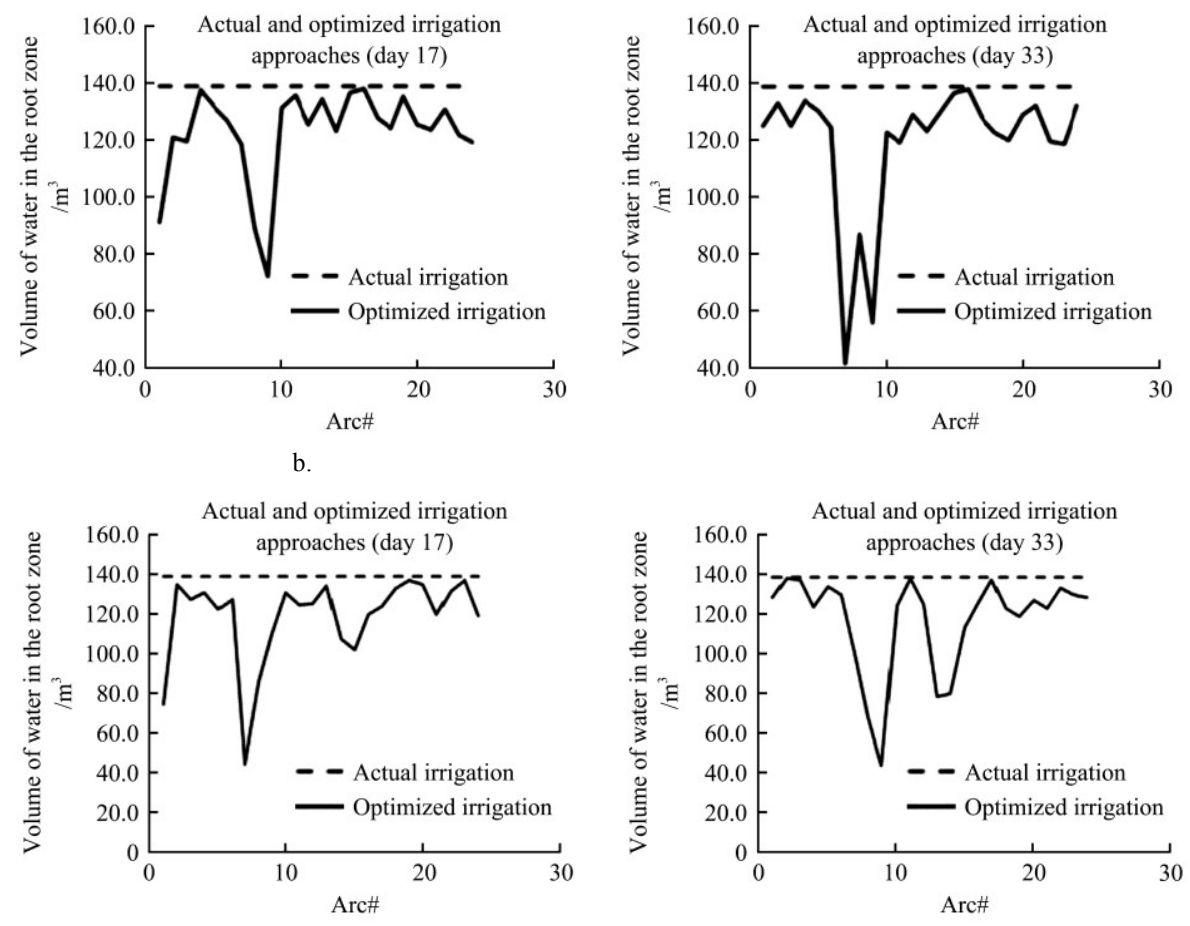

Figure 5 Water volume comparison for irrigation management and water balance simulation ${ }^{[109]}$

This section summarizes from these published literature that the effectiveness evaluation and performance influence build up the main part of agricultural irrigation operations, with the

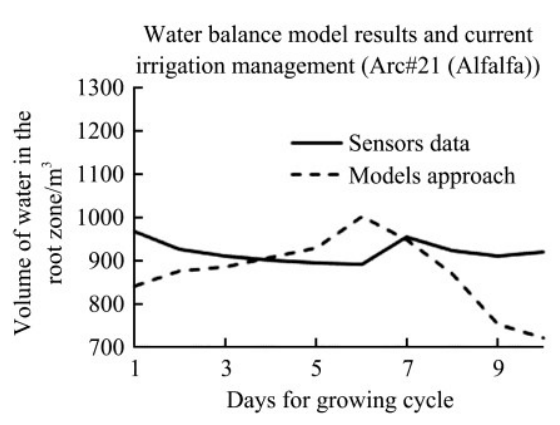

irreplaceable effect of irrigated result assessment, their major contributions could be listed as: firstly, these investigations presented a series of instructive effectiveness evaluation methods to 
explain precision irrigation mechanism and to quantify practical moisture infiltration influences on soil field; Secondly, through applying various assessing approaches to describe inherent water infiltration mechanisms and characterize specific soil-irrigation operations, they have studied the complicated influences of different effectiveness factors on the obtained cultivation outcomes or growth stages of objective crop plants; Thirdly, these investigations proposed many effective evaluation methods to reveal actual effectiveness principle, and made insightful discussions of effective schedule optimization and accurate infiltration-monitoring principles; Finally, all these researches provided original suggestions concerning the process control and effect evaluation for remarkable improvement of irrigation effectiveness. Thus, the applicable evaluation methods, the integrative designing of irrigation schedules, and the precise irrigation monitoring when considering the important mutual influences between crop cultivation, soil condition, moisture infiltration, and irrigation techniques, would be our priority efforts in the next few years.

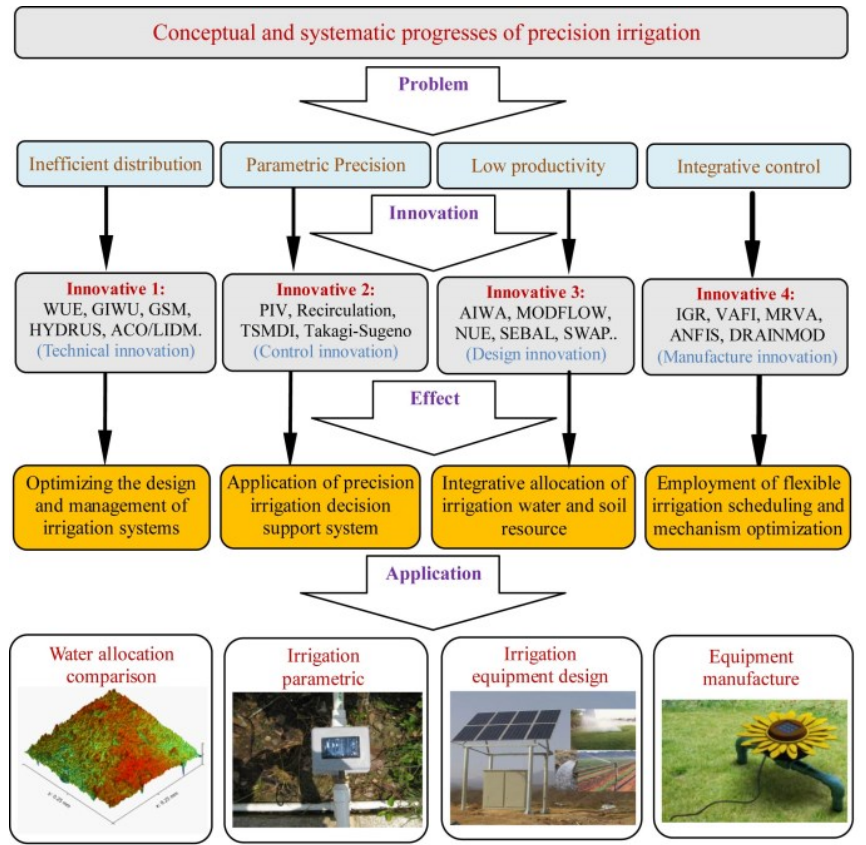

Figure 6 Research progress and equipment development summarized by ${ }^{[121]}$

\section{Future research trends}

This review focuses on representative scientific and technological issues covering the process optimization, schedule modelling, and effectiveness evaluation of agricultural irrigation, due to rapid developments in these subjects their inherent mechanisms, working principles, and constructive influences are discussed in detail, here Figure 7 gives typical subjects in the conceptual and systematic investigations, for instance, the importance and necessity, intelligent controlling, resource allocation influence, distribution mechanism, optimization design, and application characteristics of precision irrigation. Meanwhile, Figure 8 presents the literature bibliometrics diagrams on these topics from 1999 to 2020 , especially the mathematical investigation and performance estimation, soil treatment and infiltration modes, irrigation planning, and water resource distribution are emphasized. Based on the inclusion of advanced technologies in irrigation management such as soil water balance models, hydrologic models, DSSAT models, GIS-based models, ICT and IoT methods, such key subjects as remote sensing, energy consumption, decision-making, water use efficiency, sensitivity analysis, irrigation coefficient, water source allocation, and infiltration concentration, together with their focused topics and mutual-correlations, can be highlighted accordingly.

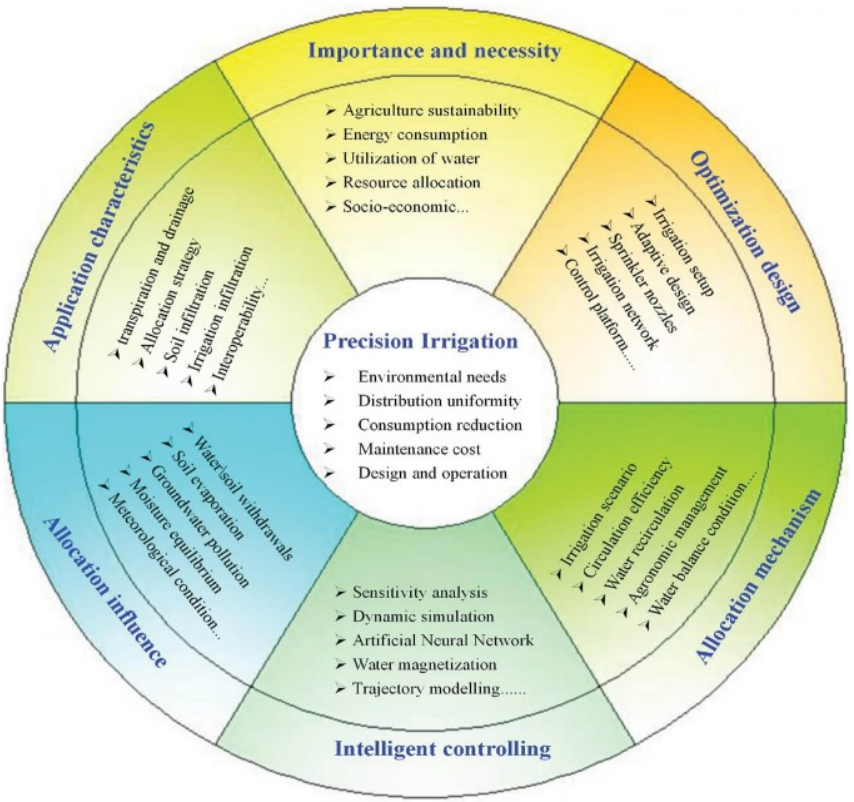

Figure 7 Conceptual and systematic investigations of precision irrigation

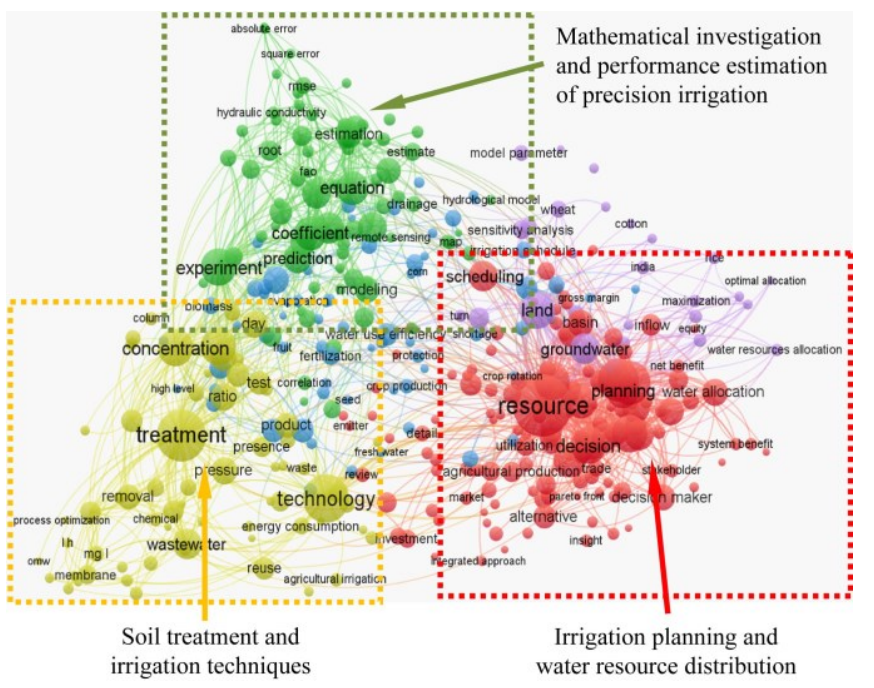

Figure 8 Literature bibliometrics diagram concerning the mostrelevant keywords in the conceptual and systematic progress of precision irrigation

Due to the advent and application of the big data technique, this Figure gives significant demonstrations covering the majority of agricultural irrigation applications. The working mechanisms currentlyinvestigated exhibit some generic properties that are worthy of test presentation and effect discussion. Thereafter the prerequisites of environmental influences encountered by them vary between inner relationships and must not be seen as independent subjects. Taking the issue of process optimization for example, which tries to achieve the goal of high agriculture sustainability and appropriate utilization of water consumption, it is observed that the necessity to use intelligent control techniques emerged, such as DSSAT, HYDRUS, Takagi-Sugeno, neuro-fuzzy, ICT, etc. In order to realize the interesting adaptation of schedule modelling for the maintenance and monitoring of precision 
irrigation, it could be shown from Figure 8 that effective irrigation scheduling approaches, including AquaCrop, AquaGIS, CROPWAT, favorably reduced the amount of water consumption in comparison with ordinary water allocation methods. Besides, in the occasion of irrigation effectiveness evaluation, with the help of intelligent control methods such as Normalized Sparse Autoencoder-Adaptive Network-based Fuzzy Inference System (NSAE-ANFIS), IoT, and WSN, the service level of irrigation application for sustainable crop production has been investigated to test the model reliability of water withdrawal and soil evaporation, thus the moisture equilibrium and groundwater infiltration monitoring could be guaranteed more easily. Their future perspectives are promising but three major problems exist:

(1) How to build up a generic precision irrigation system that enables the improvement of soil moisture uniformity and acceleration efficiency for crop cultivation? The inner structure of those optimized irrigation systems should be made generic in order to standardize the irrigation process and ease their functional design;

(2) What is the best way to integrate schedule modeling in the architecture of precision irrigation systems? As the irrigation development is speeding up, the numerical simulation and adaptive control of irrigation scheduling need to be synchronized. Also, the triggering of schedule modeling based on the behaviour of the irrigation system or the adaptive control makes the irrigation task still more difficult, as it requires the irrigation scheduling responsible for the agricultural production management;

(3) How to define a full set of irrigation effectiveness that is representative of the diversity of irrigation systems encountered and objectives expected? To guarantee the high-efficient performance of precision irrigation, effectiveness evaluation is significant with respect to management considerations, considering that evaluation of irrigation effectiveness is one of the most important subjects towards the determination of irrigation capability in various experimental conditions.

Based on these problems this section underlines, several research directions could lead to new developments for precision irrigation:

1) Data-oriented irrigation technique integrating artificial intelligence functions to exploit the self-learning ability and to ensure data connectivity. Distributed learning mechanisms could be integrated into actual precision irrigation in order to optimize the irrigation process, increase its working effectiveness, and improve the efficiency adaptability;

2) Dynamic process virtualization of precision irrigation capable of exhibiting working behaviour and decision making support while keeping a certain quality of crop cultivation, thus the optimal irrigation performance could be obtained based on current experimental irrigation conditions;

3) Real-time feedback capabilities that will integrate environmental information processing with precision irrigation system, to better monitor and plan the operation of controlled precision irrigation system, thereafter the high-efficient schedule modelling of irrigation performance could be expected;

4) Interoperability and adaptability of participant components in the precision irrigation system, which capable of operating irrigation system for multi-objective crop cultivation services in various environmental conditions with stable working performance and secure information exchanges;

5) Sustainable effectiveness management of precision irrigation, able to control the resource consumption and implementing working effectiveness of irrigation systems while fully integrating the latest technical developments and practical irrigation requirements together, including infield spatial infiltration, water drop penetration, and groundwater quality for irrigation use as well.

Since Table 4 illustrates the temporal progress of irrigation models and their influential factor contributions, these research directions bring remarkable improvements and rapid developments to build up a sustainable, secure, integrated, and evolutionary irrigation architecture exhibiting novel influential factors needed for the full application and wide promotion of precision irrigation.

Table 4 Temporal progress of precision irrigation models and their influential factor contributions

\begin{tabular}{llc}
\hline \multicolumn{1}{c}{$\begin{array}{c}\text { Factor } \\
\text { contributions }\end{array}$} & \multicolumn{1}{c}{$\begin{array}{c}\text { Development milestone of precision irrigation } \\
\text { research models along the time }\end{array}$} \\
\hline $\begin{array}{l}\text { Sustainability } \\
\text { Real-time Capabilities }\end{array}$ & $\begin{array}{l}\text { (DSSAT, 2008) } \\
\text { (AquaGIS, 2007) }\end{array}$ & (ACO/LIDM, 2009) \\
Process Virtualization & (AquaCrop, 2012) & \\
Interoperability & (DRAINMOD, 2006) & \\
Adaptability & (FAO-AZM, 2005) & (OMI, 2014) \\
Self-learning ability & (MOPECO, 2004) & (QUAL2K, 2008) \\
Connectivity & (PSO-SVM, 2003) & (SEBAL, 2005) \\
Performance Stability & & (MODFLOW, 2000) \\
Decision-making Support & & (CROPWAT, 2001) \\
\hline
\end{tabular}

All these important sections explain the conceptual and systematic progress of precision irrigation from unique perspectives of recent developments and integrated implementation. It is worth noting that the novelty of this review lies in the combination of theoretical researches and technical employments in irrigation practice, making it could be conveniently promoted in a lot of actual applications such as irrigation improvement, agricultural crop production, and relevant farming researches as well.

\section{Conclusions}

(1) This review demonstrates the latest optimization developments of precision irrigation to ensure higher productivity of crops and better environmental conditions of soil, simultaneously their promising outcomes and interactive mechanism could also be learned as well. Many effective process optimization approaches such as Takagi-Sugeno, Neuro-fuzzy inference, Adaptive Colony Optimization/Low Impact Docking Mechanism (ACO/LIDM), and genetic algorithm, have been explained, contributing to the optimum result of soil water content and evapotranspiration simulations with higher reliability and better stability. The actual optimized results demonstrated that extraordinary promotions in irrigation performance could be anticipated through employing appropriate process optimization approaches when such advanced irrigation techniques of soil water balance models, hydrologic models, DSSAT, and HYDRUS models being applied, therefore the detailed discussions and conclusive comparisons between objective irrigation influence and obtained crop productivity are greatly helpful to establish a useful research basis for irrigation improvement and efficiency promotion in return;

(2) The schedule modelling of precision irrigation has been clearly explained and comparatively discussed, including the theoretical and calculative models most suitable to illustrate its integrated mechanism verification and combined schedule 
principles, so that a set of novel modelling methods such as IoT, WSN, ICT, have been proposed and tested to develop schedule modelling and smart irrigation system in the past few years, which provided more instructive demonstrations and heuristic descriptions for the working principles of precision irrigation and the quantitative assessments of irrigation productivity, especially in representative subjects such as soil evaporation rate, soil water redistribution, and groundwater quality for irrigation use. Furthermore, in this subject many new schedule modelling algorithms have been testified for their excellent accuracy and outstanding efficiency: AquaCrop, AquaGIS, Surface Energy Balance Algorithm for Land (SEBAL), 3-D groundwater flow model (MODFLOW), QUAL2E-UNCAS, etc. It is an obvious tendency that more advanced schedule modelling methods, would be expected to enhance scheduling efficiency and agricultural productivity in the future;

(3) Recent irrigation researches have focused on the effectiveness evaluation to confirm their operational mechanisms and constructive influences. For the purpose of promoting the processing efficiency and treatment quality, reliable integration of real-time farming information is extremely significant so as to obtain better irrigation effect and higher production efficiency, simultaneously to achieve better irrigation qualities in water-soil balance, water redistribution, moisture uniformity, etc. As typical evaluation methods have already been used, such as CROPWAT, Particle Swarm Optimization-Support Vector Machine (PSO-SVM), IoT, Wireless Sensor Network (WSN) framework, and NSAE-ANFIS, to monitor and control the efficient watering effect for crop plants, a cogent understanding and process analysis of crop-soil interaction would be realized, so that an optimum integration of influential factors and operational effectiveness is guaranteed and therefore the upgraded agriculture yield could be expected thereby, otherwise the deteriorated crop growth, inferior soil quality, and low circulation efficiency of water resource would be obtained.

This review turns out that precision irrigation witnesses great development prospects and deserves considerable expectations for its outstanding working efficiency, accurate productivity management, and stable product quality. It drafts the comprehensive development picture and latest investigation status on typical precision irrigation techniques. The conceptual and systematic progress of precision irrigation in process mechanisms, effectiveness improvement, intelligent monitoring, integrative controlling, and automated equipment, are the most critical preference areas and focused frontiers need to be explored for its upcoming developments.

\section{Acknowledgements}

The authors acknowledge the funding received from the following science foundations: National Natural Science Foundation of China (51975136, 51575116, U1601204, 52075109), National Key Research and Development Program of China (2018YFB2000501), China National Spark Program (2015GA780065), the Science and Technology Innovative Research Team Program in Higher Educational Universities of Guangdong Province (2017KCXTD025), the Innovative Academic Team Project of Guangzhou Education System (1201610013), the Special Research Projects in the Key Fields of Guangdong Higher Educational Universities (2019KZDZX1009), the Science and Technology Research Project of Guangdong Province
(2017A010102014, 2016A010102022), the Science and Technology Research Project of Guangzhou (201707010293), and Guangzhou University Research Project (YJ2021002), which are all appreciated for supporting this work. The authors also want to thank the editors for their hard work and the referees for their kind comments and valuable suggestions to improve this paper.

\section{[References]}

[1] Zhao Z, Li B, Feng X, Yao M, Li C. Parameter estimation and verification of DSSAT-cropgro-tomato model under different irrigation levels in greenhouse. J. Appl. Eco., 2018; 29(6): 2017-2027.

[2] Li M, Du Y, Zhang F, Bai Y, Fan J, Zhang J. Simulation of cotton growth and soil water content under film-mulched drip irrigation using modified Csm-Cropgro-Cotton model. Agr. Water Management, 2019; 218: 124-138.

[3] Zurweller B A, Rowland D L, Mulvaney M J, Tillman B L, Migliaccio K, Wright D. Optimizing cotton irrigation and nitrogen management using a soil water balance model and in-season Nitrogen applications. Agr. Water Manag., 2019; 216: 306-314.

[4] Khalid A A, Abdalhaleem A H, ElKamil T, Ahmed G K, Rangaswamy M, Fahad A, et al. Impacts of center pivot irrigation system uniformity on growth of potato crop and residual soil Nitrogen. Int J Agric \& Biol Eng, 2019; 12(1): 126-131.

[5] Opan M. Irrigation-energy management using a DPSA-based optimization model in the Ceyhan basin of turkey. J. Hydro., 2010; 385(1-4): 353-360.

[6] Wang B, Zhang Z Y, Zhang G H, Chen Z P. Free search: A novel algorithm for optimizing irrigation schedule. Adv. Water Sci., 2008; 19(5): 736-741.

[7] Jaouher C, Abderrahmen Z, Mohamed J. Identification of an irrigation station using hybrid fuzzy clustering algorithms based on particle swarm optimization. 12th Int. Multi-conference on Systems, Signals \& Devices, 2015. doi: 10.1109/SSD.2015.7348186

[8] Ahmed M, Gaber E, El-Nobi A. Optimal operation of renewable energy irrigation system using particle swarm optimization. J. Eng. Appl. Sci., 2018; 13(24): 9318-9327.

[9] Wicha S, Sureephong P. The development of IoT-wetting front detector (IoT-WFD) for efficient irrigation management and decision support system. Conference on Joint Int. Conference on Digital Arts. 2019. doi 10.1109/ECTI-NCON.2019.8692278

[10] Ren C, Li Z, Zhang H. Integrated multi-objective stochastic fuzzy programming and ahp method for agricultural water and land optimization allocation under multiple uncertainties. J. Cleaner Production, 2019; 210(2): 12-24.

[11] Sahebjamnia N, Torabi S A. A fuzzy stochastic programming approach to solve the capacitated lot size problem under uncertainty. In: IEEE Int. Conference on Fuzzy Systems, 2011; pp.2327-2334. doi: 10.1109/FUZZY.2011.6007653

[12] Afshar M H, Rajabpour R. Application of local and global particle swarm optimization algorithms to optimal design and operation of irrigation pumping systems. Irrig. Drain., 2009; 58: 321-331

[13] Gonzal R, Daccache A, Rodriguez D J A, Camacho P E, Kno J W. Modelling impacts of precision irrigation on crop yield and in-field water management. Prec. Agric. 2018; 19(3): 497-512.

[14] Enrique P, Luciano M. Modernization and optimization of irrigation systems to increase water productivity. Agr. Water Manag., 2006; 80(1-3): 100-116.

[15] José F, José A, José M, Eulogio L. MOPECO: An economic optimization model for irrigation water management. Irrig. Sci., 2004; 23(2): 61-75.

[16] Jiao X Y, Wang W H, Wang Z T, Liu Y. Robust design of border irrigation based on the Taguchi method. J. Hydraul. Eng., 2013; 44(3): 349-354. (in Chinese)

[17] Hideki W, Yoshinari K, Satoshi K. Control of pythium and phytophthora rot on potted flowers by inorganic silver antibacterial ceramics in sub-irrigation system. Ann. Report of the Kansai Plant Protection Soc., 2008; 50: 87-89.

[18] Raju S, Kumar N. Taguchi methodology for multi-criterion decision making in irrigation planning. Agr. Systems., 2006; 62(2): 117-129.

[19] Ma J Q, Cui B F, Liu L, He P F. Application of fuzzy comprehensive evaluation based on improved analytic hierarchy process in optimization 
of irrigation scheme. Water Saving Irrig., 2017; 8: 34-43. (in Chinese)

[20] Luo J, Qiu Y. Fuzzy comprehensive evaluation for decision making of water saving irrigation system. Wuhan Univ. J. Nat. Sci., 2003; 8(3A): 837-841.

[21] Fang Y, Yang P, Song S, Du J, Su Y. Secondary fuzzy comprehensive evaluation model for ecosystem health of irrigation district and its application. Transactions of the CSAE, 2011; 27(11): 199-205. (in Chinese)

[22] Margarita G, Elías F. Combining the simulation crop model AquaCrop with an economic model for the optimization of irrigation management at farm level. Euro. J. Agron., 2012; 36(1): 21-31.

[23] Geerts S, Raes D, Garcia M. Using AquaCrop to derive deficit irrigation schedules. Agr. Water Manag., 2010; 98(1): 213-216.

[24] Ahmadi S H, Mosallaeepour E, Kamgar-Haghighi A A, Sepaskhah A R. Modeling maize yield and soil water content with AquaCrop under full and deficit irrigation managements. Water Res. Manag., 2015; 29(8): 2837-2853.

[25] Qiu J, Cheng J, Zhang R, Zhang L. Application of traditional decomposition-amalgamation method based on DPSA in optimal regulation of parallel pumping stations. J. Drain. Irrig. Mach. Eng., 2011; 29(6): 497-502.

[26] Nguyen D, Dandy G, Maier H, Ascough J. Improved ant colony optimization for optimal crop and irrigation water allocation by incorporating domain knowledge. J. Water Res. Plan. Manag., 2016; 142(9): 04016025.

[27] Marouane S, Alahmari F, Akaichi J. Ant colony optimization approach for optimizing irrigation system layout: case of gravity and collective network. Int. Conference on Intelligent Interactive Multimedia Systems and Services, 2018; 2017: 323-332

[28] Lin P, Liu X L, Chen H X, Kim J X. Ant colony optimization analysis on overall stability of high arch dam basis of field monitoring. Sci. World J., 2014; 25(6): 483243. doi:10.1155/2014/483243

[29] Sayd R M, Amabile R F, Fábio G F, Coelho M C, Montalvo A. Genetic parameters and agronomic characterization of elite barley accessions under irrigation in the Cerrado. Acta Entiarum Agr., 2019; 41(1): 42630. doi:10.4025/actasciagron.v41i1.42630

[30] Ashofteh P S, Bozorg-Haddad O, Loáiciga H A. Application of bi-objective genetic programming (BO-GP) for optimizing irrigation rules using two reservoir performance criteria. Int. J. River Basin Manag., 2019; 19(10): 1-34.

[31] Ghobadian R, Hazeri A, Fatemi E. Optimization of pressurized irrigation network pipe diameters using genetic algorithm based on integer numeric (Case study: Ismail Abad Network in Lorestan). J. Soil Water Cons., 2019; 25(4): 207-224.

[32] Dash J K, Acharya M M. Solving multi-objective fuzzy probabilistic programming problem. J. Intel. Fuzzy Systems Appl. Eng. Technol., 2014; 26(2): 935-948.

[33] Ali J, Saeed M, Tabassam M F, Iqbal S. Controlled showering optimization algorithm: an intelligent tool for decision making in global optimization. Comput. Math. Organization Theory, 2019; 25(2): 132-164.

[34] Bahrami M, Bozorg-Haddad O, Chu X. Application of cat swarm optimization algorithm for optimal reservoir operation. J. Irrig. Drain. Eng., 2018; 144(1): 04017057. doi: 10.1061/(ASCE)IR.1943-4774.000 1256

[35] Shang G L. Optimization of irrigation channel section based on cat swarm algorithm and analysis on design parameters. J. Drain. Irrig. Machinery Eng., 2016; 34(2): 146-150.

[36] Mahmood A, Mahdi G, Behrouz M F, Mohammad S. Surface irrigation simulation-optimization model based on meta-heuristic algorithms. Agr. Water Manag., 2018; 201(3): 46-57.

[37] Haddad O B, Tabari M M R, Fallah-Mehdipour E, Marino M A. Groundwater model calibration by meta-heuristic algorithms. Water Res. Manag., 2013; 27(7): 2515-2529.

[38] Chetty S, Adewumi A O. On the performance of new local search heuristics for annual crop planning: case study of the Vaalharts irrigation scheme. J. Exp. Theor. Art. Int., 2015; 27(2): 159-179.

[39] Nguyen B H, Mitsuyasu Y. Improvement in irrigation water use efficiency: a strategy for climate change adaptation and sustainable development of Vietnamese tea production. Environ. Dev. Sustain. 2017; 19(4): 1247-1263.

[40] Hintsa L G, Kidane W, Kiflom D K. Optimizing yield and water use efficiency of furrow-irrigated potato under different depth of irrigation water levels. Sustainable Water Resources Manag., 2018; 4(4): 10431049

[41] Muhammad U R, Abid L, Muhammad A. Optimizing irrigation deficit of multipurpose cascade reservoirs. Water Resour. Manag., 2018; 32(5): 1675-1687.

[42] Meissner R, Rupp H, Haselow L. Use of lysimeters for monitoring soil water balance parameters and nutrient leaching. In: Clim. Change Soil Interactions, Elsevier Ltd., 2020; pp.171-205. doi: 10.1016/ B978-0-12-818032-7.00007 -2

[43] Mao W, Yang J, Zhu Y, Ye M, Liu Z, Wu J. An efficient soil water balance model based on hybrid numerical and statistical methods. J. Hydrol., 2018; 559: 721-735.

[44] Vakhtang S, Jiri J S, Gerrit H. Coupling DSSAT and Hydrus-1D for simulations of soil water dynamics in the soil-plant-atmosphere system. J. Hydro.Hydromech., 2018; 66(2): 223-245.

[45] Atikur R, Mohammad A M, Selina B. Climate change impact assessment on three major crops in the north-central region of Bangladesh using DSSAT. Int J Agric \& Biol Eng, 2018; 11(4): 135-143.

[46] Liu Y, Guan X K, Yang M D, Ding C M, Wang T. Optimizing the summer maize irrigation schedule in north Henan province based on the DSSAT model. Acta Ecologica Sinica,. 2019; 39(14): 5348-5358.

[47] Moallim A, Hadi M, Nasehir Y, Mohamed Z, Hasfalina M. An assessment of the vertical movement of water in a flooded paddy rice field experiment using Hydrus-1D. Water, 2018; 10(6): 783-786.

[48] Karandish F, Darzi-Naftchali A, Jiří Š. Application of Hydrus (2D/3D) for predicting the influence of subsurface drainage on soil water dynamics in a rainfed-canola cropping system. Irrig. Drain., 2018; 67(SI): 29-39.

[49] Coppola D, Sengouga L. Identifying optimal irrigation water needs at district scale by using a physically based agro-hydrological model. Water, 2019; 11(4): 841-851.

[50] Brunetti G, Simunek J, Bautista E. A hybrid finite volume-finite elemen model for the numerical analysis of furrow irrigation and fertigation. Comput. Elect. Agr., 2018; 150: 312-327.

[51] Hu C, Wang X, Wang S, Lu B, Tang X. Impact of agricultural residual plastic film on the growth and yield of drip-irrigated cotton in arid region of Xinjiang, China. Int J Agric \& Biol Eng, 2020; 13(1): 160-169.

[52] Bhunia G S, Keshavarzi A, Shit P K, Omran E, Bagherzadeh A Evaluation of groundwater quality and its suitability for drinking and irrigation using GIS and geostatistics techniques in semiarid region of Neyshabur, Iran. Appl. Water Sci., 2018; 8(6): 168-178.

[53] Asfandyar S, Shihua Q, Muhammad Z, Audil R, Muhammad A T, Umer A. Hydrochemical characteristic and water quality assessment for drinking and agricultural purposes in district Jacobabad, Lower Indus Plain, Pakistan. Int J Agric \& Biol Eng, 2018; 11(2): 115-121.

[54] Feng Q, Zou W, Fan P, Zhang C, Wang X. Design and test of robotic harvesting system for cherry tomato. Int J Agric \& Biol Eng, 2018; 11(1): 96-100.

[55] Golam S A S, So K, Daisuke K, Shamsuddin S, Nepal C D. Optimum abstraction of groundwater for sustaining groundwater level and reducing irrigation cost. Water Resour. Manag., 2017; 31(6): 1947-1959.

[56] González P R, Camacho P E, Montesinos P, Rodríguez D J A. Optimization of irrigation scheduling using soil water balance and genetic algorithms. Water Resour. Manag., 2016; 30(8): 2815-2830

[57] Liang Z W, Liao S P, Wen Y H, Liu X C. Working parameter optimization of strengthen waterjet grinding with the orthogonalexperiment-design-based ANFIS. J. Intell. Manuf., 2019; 30(2): 833-854.

[58] Xu J Z, Peng S Z, Yang S H, Yu Y M. Coupled model of stomatal conductance- photosynthesis- transpiration for paddy rice under watersaving irrigation. Ar. Agron. Soil Sci., 2014; 60(2): 163-181.

[59] Liang Z W, Xie B H, Liao S P, Zhou J H. Concentration degree prediction of AWJ grinding effectiveness based on turbulence characteristics and the improved ANFIS. Int. J. Adv. Manuf. Technol., 2015; 80(5): 887-905.

[60] Liu X C, Liang Z W, Wen G L, Yuan X F. Waterjet machining and research developments: A review. Int. J. Adv. Manuf. Technol., 2018; 102(5): 1257-1335

[61] Wanjiru E M, Xia X H. Energy-water optimization model incorporating rooftop water harvesting for lawn irrigation. Appl. Energy, 2015; 160(12): 521-531.

[62] González P R, Camacho P E, Montesinos P, Rodríguez D, Juan A. Optimization of water demand forecasting by artificial intelligence with short data sets. Bios. Eng., 2019; 177(1): 59-66. 
[63] Kamil I A, Ojoawo O. Smart irrigation: an ICT application in agriculture. Int. J. Eng. Sci., 2019; 8(3 Series I): 53-58.

[64] Parameswaran B, Abdul H R A S, Abdur R T K M, Karthikeyan A K, Keerthi J. Automated IoT based indoor irrigation. Int. J. Sci. Res. Sci. Eng. Techn., 2019; 3: 68-71.

[65] Kamienski C, Soininen J P, Taumberger M, Dantas R, Toscano A, Salmon Cinotti T. Smart water management platform: IoT-based precision irrigation for agriculture. Sensors, 2019; 19(2): 276-286.

[66] Edgar H G, Juliana S B, Javier A, Carbonell G. IoT network applied to agriculture: monitoring stations for irrigation management in soils cultivated with sugarcane. Int. Conf. ICT for Adapting Agriculture to Climate Change, 2018. doi: 10.1007/978-3-030-04447-3_17

[67] Zhu N Y, Liu X, Liu Z Q, Hu K, Wang Y K, Tan J L, et al. Deep learning for smart agriculture: Concepts, tools, applications, and opportunities. Int J Agric \& Biol Eng, 2018; 11(4): 32-44.

[68] Swathi M R. An overview of IoT towards irrigation system. Ind. J. Public Health Res. Develop., 2018; 9(11): 1184-1198.

[69] Ping H, Wang J H, Ma Z H, Du Y F. Mini-review of application of IoT technology in monitoring agricultural products quality and safety. Int $\mathrm{J}$ Agric \& Biol Eng, 2018; 11(5): 35-45.

[70] Hong S, Malaterre P O, Belaud G, Dejean C. Optimization of irrigation scheduling for complex water distribution using mixed integer quadratic programming (MIQP). 10th Int. Conference on Hydroinformatics, 2012. doi: hal-00783214

[71] Kamaruddin B, Zabiri H. Investigating MIQP-based MPC performance for stiction compensation. Aust. J. Basic Appl. Sci., 2015; 9(32): 78-84.

[72] Zheng X J, Sun X L, Li D, Cui X T. Lagrangian decomposition and mixed- integer quadratic programming reformulations for probabilistically constrained quadratic programs. Euro. J. Op. Res., 2012; 221(1): 38-48.

[73] Tian Z, Wu W C, Zhang B M. A mixed integer quadratic programming model for topology identification in distribution network. IEEE Trans. Power Systems, 2015; 31(1): 1-2

[74] Jia X F, Lu W X, Yang Z P, Long Y Q, Shi F H. Study on application of simulated annealing algorithm to solve optimization model of irrigation schedule. Water Saving Irrig., 2010; 8: 64-68. (in Chinese)

[75] Cao R, Yan W, Yang Y S. Research on optimization of crop irrigation decisions based on genetic simulated annealing algorithm. J. Agr. Mech. Res., 2011; 10: 37-30.

[76] Gong Y X, Wang L G. Optimal design of planet transmission mechanism in agricultural machinery based on bee colony and invasive weed optimization. Agr. Res. Arid Areas., 2015; 33(2): 283-286.

[77] Mohammad J M, Bahram S K. New discrete particle swarm optimization applied to the design of pressurized irrigation networks. J. Irrig. Drain. Eng., 2017; 143(1): 04016071. doi:10.1061/(asce)ir.19434774.0001110

[78] Rojas K W, DeCoursey D G. Predicting water quality as affected by ET using the root zone water quality model. Irrigation and Drainage: Saving a Threatened Resource-In Search of Solutions, ASCE, 2015.

[79] Fallah M E, Haddad O B, Marino M A. Discussion of performance of shuffled frog-leaping algorithm in finance-based scheduling. J. Comput. Civil Eng., 2014; 28(2): 327-329.

[80] Haddad O B, Hamedi F, Fallah M E, Orouji H, Mario M A. Application of a hybrid optimization method in Muskingum parameter estimation. J. Irrig. Drain. Eng., 2015; 142(8): 9-26.

[81] Kang L J, Zhang R Z, Wu L L. Study on application of SFLA- based irrigation schedule optimization. Water Saving Irrig., 2012; 25(5): 73-75. (in Chinese)

[82] Li X P, Zhang J B, Liu J T, Liu J L, Zhu A N, Lv F, et al. A modified checkbook irrigation method based on GIS-coupled model for regional irrigation scheduling. Irrig. Sci., 2011; 29(2): 115-126.

[83] Cisty M, Bajtek Z, Celar L. A two-stage evolutionary optimization approach for an irrigation system design. J. Hydroinformatics, 2017; 19(1-2): 115-122.

[84] Qie Z H, Han L M, Wu X M. Optimization of crop irrigation quantity and irrigation date based on the improved NSGA-II. Transactions of the CSAM, 2011; 42(5): 106-110. (in Chinese)

[85] Patel C, Nema A K, Singh R S, Yadav M K, Singh S M. Evaluation of DSSAT-CERES model for irrigation scheduling of wheat crop in Varanasi region of Uttar Pradesh. J. Agro., 2017; 19(2): 120-124.

[86] Malik W, Dechmi F. DSSAT modelling for best irrigation management practices assessment under Mediterranean conditions. Agr. Water Manag., 2019; 216(C): 27-43.

[87] Lamyaa M, Negm M, Youssef A. DRAINMOD-DSSAT simulation of the hydrology, nitrogen dynamics, and plant growth of a drained corn field in Indiana. J. Irrig. Drain. Eng., 2014; 14(8): 04014026.. doi: 10.1061/ (ASCE)IR.1943-4774.0000738

[88] Araya A, Kisekka I, Gowda P H, Prasad P. Evaluation of water-limited cropping systems in a semi-arid climate using DSSAT-CSM. Agr. Systems, 2017; 150: 86-98.

[89] Babel M S, Proloy D, Peeyush S. Performance evaluation of AquaCrop and DSSAT-CERES for maize under different irrigation and manure application rates in the Himalayan region of India. Agr. Res., 2018; 8(2): 207-217.

[90] Zhu L, Shi H B, Wang N, Dai J X, Yan J W, Fu X J. Crop water requirement and optimization of irrigation system of InterCrop wheat and maize by ISAREG model. J. Irrig. Drain., 2012; 31(4): 36-31.

[91] Cheng G Y, Shi H B, Li R P, Wang C G, Wang Z C, Yu H, et al Research on the optimal irrigation schedule of semi-fixed sprinkler soybean based on the ISAREG model. J. Irrig. Drain., 2015; 34(12) $52-58$

[92] Tong C F, Li H P, Bai B T, Zheng H X, Wang J, Zhang Y. The optimal irrigation system of Alfalfa based on win ISAREG model. Chin. Agr. Sci. Bulletin, 2016; 32(24): 113-118. (in Chinese)

[93] Pawar G S, Kale M U, Lokhande J N. Response of AquaCrop model to different irrigation schedules for irrigated cabbage. Agric. Res., 2017 6(1): 73-81.

[94] Sepideh A, Javad A, Mohammad G. A technical model for reclaimed water reuse in precision irrigation: A case study in Kordkuy, Iran Environ. Earth Sci., 2018; 77(2): 90-92.

[95] Mulubrehan K, Gebretsadikan T G. Yield and water use efficiency of furrow irrigated potato under regulated deficit irrigation, AtsibiWemberta, North Ethiopia. Agric. Water Manag., 2016; 170(5): 133139 .

[96] Conesa M R, Falagan N, De la Rosa J M, Aguayo E, Domingo R, Perez P A. Post-version deficit irrigation regimes enhance berry coloration and health-promoting bioactive compounds in 'Crimson Seedless' table grapes. Agric. Water Manag., 2016; 163(1): 9-18.

[97] Tsang W, Jim C Y. Applying artificial intelligence modelling to optimize green roof irrigation. Energy Build., 2016; 127(9): 360-369.

[98] Linker R, Sylaios G. Efficient model-based sub-optimal irrigation scheduling using imperfect weather forecasts. Comput. Elect. Agric., 2016; 130(11): 118-127.

[99] Vicente T, Patrick W, Guido W, Felipe C. Evaluation of reservoir operation strategies for irrigation in the Macul Basin, Ecuador. J. Hydro., 2016; 5(3): 213-225.

[100] Henrique B D, Paulo C S. Dimensioning the impact of irrigation on sugarcane yield in Brazil. Sugar Technol. 2019; 21(1): 29-37.

[101] Luo Y F, Fu H L, Xiong Y J, Xiang Z, Wang F, Bugingo Y C, et al. Effects of water-saving irrigation on weed infestation and diversity in paddy fields in East China. Paddy Water Environ., 2017; 15(3): 593-604.

[102] Christopher M, Gunnar L. Multivariate analysis to assess the impact of irrigation on groundwater quality. Environ. Earth Sci., 2019; 78(5): 274. doi: 10.1007/s12665-019-8274-4

[103] Liang Z W, Liu X C, Ye B Y, Xie B H. Adaptive prediction of abrasive impacting pressure effectiveness in strengthen jet grinding using NSAE-ANFIS. Int. J. Adv. Manuf. Technol., 2020; 106(7): 2805-2828.

[104] Keiji T, Yoichi F. Evaluation of the effects of irrigation water on groundwater budget by a hydrologic model. Paddy Water Environ., 2019; 17(3): 439-446

[105] Fang X B, Zhang J Y, Chen Y X, Xu X Y. QUAL2K model used in the water quality assessment of Qiantang River, China. Water Environ. Res. 2008; 80 (11): 2125-2133.

[106] Liang Z W, Liu X C, Wen G L, Yuan X F. Influence analysis of sprinkler irrigation effectiveness using ANFIS. Int J Agric \& Biol Eng, 2019; 12(5): 135-148.

[107] Allam A, Tawfik A, Yoshimura F A. Simulation-based optimization framework for reuse of agricultural drainage water in irrigation. J. Environ. Manag., 2016; 172(5): 82-96.

[108] Liang Z W, Tan S, Liao S, Liu X. Component parameter optimization of strengthen waterjet grinding slurry with the orthogonal-experimentdesign-based ANFIS. Int. J. Adv. Manuf. Technol., 2016; 90(1-4): 1-25.

[109] Leila H, Alfonso T, Mac M. Assessment of optimal irrigation water allocation for pressurized irrigation system using water balance approach, learning machines, and remotely sensed data. Agric. Water Manag., 2015; 153(5): 42-50. 
[110] Nazmi D, Koksal A, Mesut I, Ruhi B, Nuri A, Alpaslan S, et al. Assessment of different irrigation strategies on yield and quality characteristics of drip irrigated pomegranate under Mediterranean conditions. Irrig. Sci., 2018; 36(2): 87-96.

[111] Liang Z W, Liu X C, Zou T, Xiao J R. Adaptive prediction of water droplet infiltration effectiveness of sprinkler irrigation using regularized sparse autoencoder-adaptive network-based fuzzy inference system (RSAE-ANFIS). Water, 2021; 13: 791. doi: 10.3390/w13060791

[112] Önder Ö. Risk assessment for determining best design alternative in a state-owned irrigation project in Turkey. KSCE J. Civil Eng., 2016; 20(1): 109-120.

[113] Kidane W, Hintsa L G, Kiflom D K. Optimizing irrigation water levels to improve yield and water use efficiency of vegetables: case study of tomato. Sustain. Water Resour. Manag., 2019; 5(2): 737-742.

[114] Albalawneh A, Chang T K, Chou C S. Impacts on soil quality from long-term irrigation with treated waste water. Paddy Water Environ., 2016; 14(2): 289-297.

[115] Smith R J, Uddin J M, Gillies M H, Moller P, Clurey K. Evaluating the performance of automated bay irrigation. Irrig. Sci., 2016; 34(3): $175-185$.

[116] Safi S Z, Kamgar- Haghighi A A, Zand-Parsa E Y, Honar T. Evaluation of yield, actual crop evapotranspiration and water productivity of two canola cultivars as influenced by transcultivation and seeding and deficit irrigation. Int. J. Plant Prod., 2019; 13: 23-33.

[117] Adejumobi M A, Awe G O, Abegunrin T P, Oyetunji O M, Kareem T S. Effect of irrigation on soil health: a case study of the Ikere irrigation project in Oyo State, southwest Nigeria. Environ. Monit Assess., 2016; 188(12): 696. doi:10.1007/s10661-016-5628-1

[118] Naor A, Birger R, Peres M, Gal Y, Abd Elhadi F, Haklay A, et al. The effect of irrigation level in the kernel dry matter accumulation period on almond yield, kernel dry weight, fruit count, and canopy size. Irrig. Sci., 2018; 36(1): 1-8

[119] Warwick R A, Ketema T Z. Diurnal effects on the efficiency of drip irrigation. Irrig. Sci. 2017; 35(2): 141-157.

[120] Mojtaba K, Sayyed M J M, Pooya S, Reza N V. Evaluation of dripper clogging using magnetic water in drip irrigation. Appl. Water Sci., 2018; 8(6): 81. doi:10.1007/s13201-018-0725-7

[121] Liang Z W, Shan S Y, Liu X C, Wen Y H. Fuzzy prediction of AWJ turbulence characteristics by using multi-phase flow models. Eng. Appl. Comp. Fluid, 2017; 11(1): 225-257.

[122] David A C, Neil C H, Bryan G H, Kendall C D. Leaf temperature of maize and crop water stress index with variable irrigation and nitrogen supply. Irrig. Sci., 2017; 35(6): 549-560.

[123] Ramesh M V, Prabha R, Sinitambirivoutin E. Design and development of an IoT based smart irrigation and fertilization system for chilli farming. 2018 Int. Conference on Wireless Communications, Signal Processing and Networking (WiSPNET), 2018. doi: 10.1109/ WiSPNET.2018.8538568

[124] Vinoth M, Vithiya G. Farm field monitoring and irrigation automation using IoT. Int. J. Eng. Technol., 2018; 26(7): 53-56.

[125] Keswani B, Mohapatra A G, Mohanty A, Khanna A, Rodrigues J, Gupta D. Adapting weather conditions based IoT enabled smart irrigation technique in precision agriculture mechanisms. Neur. Comput. Appl., 2018; 31(SI): 277-292.

[126] Kerkar R, Bhosale K, Khanche G, Pillai M. IoT based intelligent irrigation system using Intel Edison and fuzzy inference system. Int. J Comput. Sci. Eng., 2019; 7(5): 604-607.

[127] Munir M S, Bajwa I S, Naeem M A, Ramzan B. Design and implementation of an IoT system for smart energy consumption and smart irrigation in tunnel farming. Energies, 2018; 11(12): 3427 . doi $10.3390 /$ en 11123427

[128] Ge J K, Cai C D, Liu Y F, Gong X W. Effect of irrigation time on the growth rate and indoor environment of greenhouse eggplant. J. Inst. Eng India Ser. A., 2018; 99(4): 647-651.

[129] Li Z H, Hao Z C, Shi X G, Stephen J D, Li J Y, Chen S C, et al. An agricultural drought index to incorporate the irrigation process and reservoir operations: A case study in the Tarim River Basin. Global Plane. Change, 2016; 143(8): 10-20.

[130] Pawlowski A. Evaluation of event-based irrigation system control scheme for tomato crops in greenhouses. Agric. Water Manag., 2017; 183(3): 16-25. 